\title{
An investigation of the potential application of chitosan/aloe-based membranes for regenerative medicine
}

\author{
S.S. Silva ${ }^{a, b, *}$, E.G. Popa ${ }^{a, b}$, M.E. Gomes ${ }^{a, b}$, M. Cerqueira ${ }^{a, b}$, A.P. Marques ${ }^{a, b}$, S.G. Caridade ${ }^{a, b}$, P. Teixeira ${ }^{c}$, \\ C. Sousa ${ }^{c}$, J.F. Mano ${ }^{\mathrm{a}, \mathrm{b}}$, R.L. Reis ${ }^{\mathrm{a}, \mathrm{b}}$ \\ a 3B's Research Group - Biomaterials, Biodegradables and Biomimetics, University of Minho, Headquarters of the European Institute of Excellence on Tissue Engineering \\ and Regenerative Medicine, AvePark, Caldas das Taipas, 4806-909 Guimarães, Portugal \\ b ICVS/3B's - PT Government Associate Laboratory, Braga, Guimarães, Portugal \\ ${ }^{\mathrm{c}}$ Institute for Biotechnology and Bioengineering, Centre of Biological Engineering, University of Minho, Campus de Gualtar, $4710-057$ Braga, Portugal
}

\section{A R T I C L E I N F O}

\section{Article history:}

Received 17 October 2012

Received in revised form 14 February 2013

Accepted 14 February 2013

Available online $\mathrm{xxxx}$

\section{Keywords:}

Aloe vera gel

Chitosan

Wound dressings

Dermal fibroblasts

Membrane

\begin{abstract}
A B S T R A C T
A significant number of therapeutics derived from natural polymers and plants have been developed to replace or to be used in conjunction with existing dressing products. The use of the therapeutic properties of aloe vera could be very useful in the creation of active wound dressing materials. The present work was undertaken to examine issues concerning structural features, topography, enzymatic degradation behavior, antibacterial activity and cellular response of chitosan/aloe vera-based membranes. The chitosan/aloe vera-based membranes that were developed displayed satisfactory degradation, roughness, wettability and mechanical properties. A higher antibacterial potency was displayed by the blended membranes. Moreover, in vitro assays demonstrated that these blended membranes have good cell compatibility with primary human dermal fibroblasts. The chitosan/aloe vera-based membranes might be promising wound dressing materials.
\end{abstract}

(c) 2013 Acta Materialia Inc. Published by Elsevier Ltd. All rights reserved.

\section{Introduction}

In recent years the inclusion of medicinal plants in alternative medicine has been increasing in our society as a way to improve people's quality of life [1]. This interest arises from the therapeutic properties of plants, which are useful in healing various diseases, with the advantage of being $100 \%$ natural. A good example is the use of aloe vera $(\mathrm{AV})$, a tropical plant belonging to the family Liliaceae, as a healing accelerator on small wounds and burns because of its antimicrobial effect and epithelizing action on damaged skin tissue [2]. The gel extracted from AV leaf has also been used as a healing agent in cosmetic products and drugs [3]. The health benefits associated with AV have been attributed to its compositional heterogeneity, containing amino acids, enzymes, vitamins, polysaccharides (pectins, cellulose, hemicellulose, glucomannan, acemannan and mannose derivatives) and other low molecular weight substances [2]. An analysis of the effects of AV regarding the requirements for wound healing, such as the maintenance of nutrients, moisture, oxygenation, control of inflammation, immunodulatory activity, epithelialization and fibroblast proliferation

\footnotetext{
* Corresponding author at: 3B's Research Group - Biomaterials, Biodegradables and Biomimetics, University of Minho, Headquarters of the European Institute of Excelllence on Tissue Engineering and Regenerative Medicine, AvePark, Caldas das Taipas, 4806-909 Guimarães, Portugal. Tel.: +351 253510900; fax: +351253510909.

E-mail address: simonesilva@dep.uminho.pt (S.S. Silva).
}

[4] indicated that AV products fulfill almost all these necessities. For example, a whole gel extract was found to have anti-inflammatory activity on carrageenan-induced edema in rat paws [5]. Other studies have shown that AV increases collagen content within the wound, supporting faster wound healing [6]. On the other hand, chitosan, a natural polymer derived by the deacetylation of chitin [7], has been widely used as a base material in the production of matrices for wound management [8]. Chitosan-based membranes have, for instance, been widely investigated as wound dressings due to their easy production and long shelf life [9] as well as the intrinsic properties of this polymer [7]. In this work the synergistic association of chitosan and native AV gel was explored as an approach to create blended membranes which could be useful as active wound dressings. Within this context issues concerning topography, structural features, degradation behavior, antibacterial activity and cellular response of chitosan/AV-based membranes were evaluated.

\section{Materials and methods}

\subsection{Materials}

Fresh whole AV (Aloe barbadensis Miller) leaves obtained from a Portuguese botanic shop were used as the raw material in all experiments. The studied leaves, between 30 and $40 \mathrm{~cm}$ long, came 
from to 4-year-old plants. Reagent grade medium molecular weight chitosan (Cht) (Sigma Aldrich, CAS 9012-76-4) was used, with a $23.4 \%$ degree of acetylation and molecular weight of $166 \mathrm{kDa}$, determined by ${ }^{1} \mathrm{H}$ NMR and SEC-MALLS, respectively. Prior to use Cht was purified using a reprecipitation method, as described previously [10]. All other chemicals were reagent grade and were used as received.

\subsection{Methods}

\subsubsection{Extraction of the gel}

Whole leaves were washed with distilled water to remove dirt from the surface. The skin was carefully separated from the parenchyma using a knife. The samples were extensively washed with distilled water to remove exudate from their surfaces. The samples were then homogenized in a blender and the homogenized mass filtered. After that the AV gel was stabilized at $65{ }^{\circ} \mathrm{C}$ for $15 \mathrm{~min}$ and stored at $4{ }^{\circ} \mathrm{C}$ prior to use.

\subsubsection{Preparation of the membranes}

Chitosan flakes were dissolved in $0.2 \mathrm{M}$ aqueous acetic acid at a concentration of $2 \mathrm{wt}$ \% to obtain a homogeneous solution. Then the solution was filtered to remove impurities. The extracted AV gel was added to the Cht solution at ratios of $2: 1$ and $1: 1 \mathrm{v} / \mathrm{w}$ Cht/AV, termed CAV and CAV1, respectively. Glycerol, a known plasticizer (water/glycerol $2.5 \mathrm{vol} . \%$ ) was also added to the blended mixture. The blended systems were kept under stirring at $4{ }^{\circ} \mathrm{C}$ for at least $3 \mathrm{~h}$. After homogenization the blended solutions were cast in Petri dishes and dried at room temperature for 4 days. Subsequently neutralization of the membranes was performed by soaking them in $4 \% \mathrm{NaOH} /$ ethanol $1: 1$ for $10 \mathrm{~min}$, followed by washing with ethanol and then with distilled water until $\mathrm{pH} 7$ was reached. This neutralization process was used in order to avoid leaching out of the AV due to its high solubility in water. The Cht membranes were neutralized using only $4 \% \mathrm{NaOH}[11]$.

\subsection{Characterization}

\subsubsection{Fourier transform infrared spectroscopy}

The infrared spectra of the powdered membranes were recorded in a FTIR spectrometer (Perkin-Elmer 1600 series). Prior to analysis the powdered membranes were mixed with potassium bromide at a ratio of 1:100 (by weight), followed by uniaxially pressing into a disk. All spectra were obtained between 4000 and $400 \mathrm{~cm}^{-1}$.

\subsubsection{Atomic force microscopy}

The samples were observed at at least three spots using tapping mode with a MultiMode sensor connected to a NanoScope, both supplied by Veeco, with non-contacting silicon nanoprobes $(\sim 300 \mathrm{kHz}$, set point $2-3 \mathrm{~V})$ from Nanosensors. All images (10 $\mu \mathrm{m}$ wide) were fitted to a plane using the third degree flatten procedure included in the NanoScope software v. 4.43r8. The surface roughness was calculated as $S_{\mathrm{q}}$ (root mean square from an average flat surface) and $S_{\text {a }}$ (average absolute distance from an average flat surface). The values are presented as means \pm standard deviations.

\subsubsection{Contact angle measurements}

The surface properties of the membranes were also investigated by means of static contact angle $(\theta)$ measurements using the sessile drop method with glycerol (polar) and diiodomethane (non-polar) (OCA, with SCA-20 software). Six measurements were carried out for each sample. The presented data is the average of six measurements. The surface energy was calculated using the Owens, Wendt, Rabel and Kaelble (OWRK) equation [12].

\subsubsection{Dynamical mechanical analysis (DMA)}

Viscoelastic measurements were performed using a TRITEC8000B dynamic mechanical analyzer (Triton Technology) in tensile mode. The measurements were carried out at $37^{\circ} \mathrm{C}$. Samples were cut into $1 \mathrm{~cm}$ square $\times 1.5 \mathrm{~cm}$ thick (measured with a micrometer) blocks. The membranes were analyzed while immersed in a liquid bath in a Teflon reservoir. The samples were clamped in the DMA apparatus and immersed in phosphate-buffered saline (PBS). The DMA spectra were obtained during a frequency scan between 0.1 and $10 \mathrm{~Hz}$ at $37^{\circ} \mathrm{C}$. The experiments were performed under constant strain amplitude $(50 \mu \mathrm{m})$. A minimum of three samples was used for each condition.

\subsubsection{Swelling and enzymatic degradation}

Swelling and degradation tests were performed by immersing all membranes in PBS containing $13.6 \mathrm{mg} \mathrm{l}^{-1}$ lysozyme (Sigma Aldrich) and PBS without enzyme at $37^{\circ} \mathrm{C}$ for up to 30 days. All experiments were conducted in triplicate and the solutions were changed every 7 days to guarantee enzyme activity during the study period. The swollen sample weights were measured after removing excess surface water by gently tapping the surface with filter paper. Water uptake was determined from the swollen state (after equilibration and eventual degradation or partial solubilization) $w_{\mathrm{s}}$ and the final dried weight $w_{\mathrm{f}}$ using Eq. (1). Each experiment was repeated three times, and the average value was considered to be the water uptake value.

water uptake $(\%)=\left(\left(w_{s}-w_{f}\right) / w_{f}\right) \times 100$

The weight loss was calculated from the initial dried weight $w_{\mathrm{i}}$ and final dried weight $w_{\mathrm{f}}$, using Eq. (2).

weight $\operatorname{loss}(\%)=\left(\left(w_{i}-w_{f}\right) / w_{i}\right) \times 100$

\subsubsection{Antibacterial activity}

Staphylococcus aureus ATCC 25923 were first grown for $24 \mathrm{~h}$ in Tryptic Soy Agar (TSA) (Merck, Darmstadt, Germany) at $37^{\circ} \mathrm{C}$. After this period $50 \mu \mathrm{l}$ of cell suspension were transferred to $30 \mathrm{ml}$ of fresh Tryptic Soy Broth (TSB) and incubated for $18 \mathrm{~h}$ (late exponential phase) at $37^{\circ} \mathrm{C}$ and 120 r.p.m. Then the cells were centrifuged (Sigma 4K10, B. Braun) for $5 \mathrm{~min}$ at 8000 r.p.m. and $4{ }^{\circ} \mathrm{C}$ and washed twice with saline solution $(0.9 \% \mathrm{NaCl})$ in distilled water. The cell suspension was adjusted to a final concentration of approximately $1 \times 10^{8} \mathrm{~S}$. aureus cells $\mathrm{ml}^{-1}$, determined from the optical density at $640 \mathrm{~nm}$. Prior to use the membranes were sterilized with ethylene oxide. Each membrane was placed in an individual well of a 24-well tissue culture plate (Sarstedt, Newton, $\mathrm{NC}$ ) containing $1 \mathrm{ml}$ of the cell suspension with $1 \times 10^{8} \mathrm{cells} \mathrm{ml}^{-1}$ in each well. The plates were incubated for $24 \mathrm{~h}$ at $37^{\circ} \mathrm{C}$ in an orbital shaker (120 r.p.m.). Assays were performed in triplicate and repeated three times. The number of colony-forming units (CFU ml ${ }^{-1}$ ) in suspension (cells not adherent on the membranes) was determined by the serial dilution method. Viable cell numbers were determined by performing 10 -fold serial dilutions of the cell suspension in each well in saline blanks and plating on TSA. Colonies were counted after $24 \mathrm{~h}$ at $37^{\circ} \mathrm{C}$. Only plates containing between 30 and 300 colonies were counted. The results are presented as $\log _{10} \mathrm{CFU} \mathrm{ml} \mathrm{m}^{-1}$ after challenge. Bactericidal activity was defined as a $3 \log _{10} \mathrm{CFU} \mathrm{ml}^{-1}(-99.9 \%)$ reduction in bacterial numbers.

2.3.6.1. Agar disk diffusion method. In the agar diffusion technique $30 \mathrm{ml}$ of Plate Count Agar (PCA) was added to a Petri dish and then $0.1 \mathrm{ml}$ of bacterial solution $\left(1 \times 10^{8}\right.$ cells $\left.\mathrm{ml}^{-1}\right)$ was placed in the center the dish and spread. After drying the membranes were punched into the agar at the center of each Petri dish. After 24, 
48 and $72 \mathrm{~h}$ incubation at $37^{\circ} \mathrm{C}$ the bacterial growth inhibition zones was measured. This test was repeated three times in triplicate.

\subsubsection{Isolation and culture of human dermal fibroblasts}

Human dermal fibroblasts (hDFs) were isolated from adult skin, normally discarded tissue after routine plastic surgery of healthy patients, in collaboration with Hospital da Prelada, Porto, Portugal, and after patient informed consent. After cutting the skin into small pieces it was incubated in $2.4 \mu \mathrm{m} \mathrm{l}^{-1}$ dispase II (Sigma) overnight, allowing separation of the dermis from the epidermis. The dermis was then incubated with $0.1 \%$ collagenase type IA (Sigma) at $37^{\circ} \mathrm{C}$ for $3 \mathrm{~h}$. The resulting single cell suspension was filtered using a $100 \mu \mathrm{m}$ cell strainer (BD Biosciences), centrifuged and, finally, the pellet was resuspended in $\alpha$ minimum essential medium $(\alpha$-MEM) (Invitrogen), supplemented with $10 \%$ fetal bovine serum (FBS) and $1 \%$ antibiotic/antimycotic $(1 \% \mathrm{~A} / \mathrm{B})$ (both Gibco, Invitrogen). the medium was changed three times a week and cells were used until passage 5 .

2.3.7.1. Cell culture. Prior to cell culture studies all membranes were sterilized using ethylene oxide. In vitro cell tests were performed using a cell suspension of hDFbs at a concentration of $2 \times 10^{4}$ cells per membrane. Cell membranes were incubated at $37{ }^{\circ} \mathrm{C}$ in a humidified $95 \%$ air and $5 \% \mathrm{CO}_{2}$ atmosphere in $\alpha$-MEM, supplemented with $10 \% \mathrm{FBS}, 2 \mathrm{mM}$ L-glutamine and $1 \% \mathrm{~A} / \mathrm{B}$. The culture medium was replaced twice a week. Three independent experiments were performed. Triplicates were used for each time point in each different test. After 1, 3, 7 and 15 days culture the medium was removed and the samples were washed with PBS and processed for alamar blue assay, calcein-AM staining and DNA quantification.

The alamarBlue ${ }^{\circledR}$ assay was performed to assess the metabolic activity of hDFs in contact with the test membranes. For this assay an alamar blue solution (alamarBlue ${ }^{\circledR}$ Cell Viability Assay Protocol, Life Technologies) was prepared, added to the medium and incubated for $4 \mathrm{~h}$ at $37^{\circ} \mathrm{C}$. The optical density (OD) was read at 570 and $600 \mathrm{~nm}$ in a multiwell microplate reader (Synergy HT, BioTek Instruments). All tests were performed using six replicates.

\subsubsection{DNA quantification. hDFb proliferation in the membranes} was determined using a fluorimetric double-stranded DNA (dsDNA) quantification assay (PicoGreen ${ }^{\circledR}$, Molecular Probes, Invitrogen). At each time point samples were transferred to $1.5 \mathrm{ml}$ microtubes containing $1 \mathrm{ml}$ of ultra-pure water, incubated for $1 \mathrm{~h}$ at $37{ }^{\circ} \mathrm{C}$ in a water-bath and then stored in a $-80^{\circ} \mathrm{C}$ freezer until use. Prior to dsDNA quantification samples were thawed and sonicated for $15 \mathrm{~min}$. Samples and standards (ranging from 0 to $1.5 \mathrm{mg} \mathrm{ml}^{-1}$ ) were prepared and mixed with PicoGreen solution at a 200:1 ratio, and placed in a white 96-well plate. Triplicates were prepared for each sample and standard. The plate was incubated for $10 \mathrm{~min}$ in the dark and fluorescence was measured in a microplate reader (BioTek) using excitation and emission wavelengths of $485 / 20 \mathrm{~nm}$ and $528 / 20 \mathrm{~nm}$, respectively. A standard curve was created and sample dsDNA values were read from the standard curve.

2.3.7.3. Calcein-AM. The viability of hDFs adherent on the membranes was analyzed after calcein-AM staining. $2 \mu \mathrm{l}$ of calcein-AM and $1 \mathrm{ml}$ of Dulbecco's modified Eagle's medium without phenol red and FBS were added to each sample, followed by 10 min incubation at $37^{\circ} \mathrm{C}$. Live cells were stained green due to enzymatic conversion of the non-fluorescent cell permeant calcein-AM to fluorescent calcein. Fluorescent cells were visualized with a Imager-Z1M fluorescence microscope (Zeiss, Germany).

\subsection{Statistical analysis}

Statistical analysis of the quantitative data was conducted using two-way ANOVA with Bonferroni's post test using GraphPadPrism v. 5.0 for Windows (GraphPad Software, San Diego, CA). Differences between the groups at $p<0.05$ were considered to be statistically significant.

\section{Results and discussion}

Chitosan/AV-based membranes were successfully produced using of 2:1 and $1: 1 \mathrm{v} / \mathrm{w}$ ratios of Cht to native AV. Table 1 shows the physical properties of the membranes. The blended membranes obtained had a yellowish color, and good homogeneity and mechanical stability. Structural differences between Cht and $\mathrm{AV}$ as well as the changes that occurred in the developed membranes were analyzed by FTIR analysis. In the Cht spectrum (Fig. 1a) the main characteristic absorption bands of this polymer appear at 1657 ( $\mathrm{C}=\mathrm{O}$ stretching), $1582\left(\mathrm{NH}_{2}\right.$ stretching) and $1090-1050 \mathrm{~cm}^{-1}$ (C-O-C glycosidic bond) [13]. The main peaks of AV (Fig. 1b) can be observed at 1731 (O-acetyl esters), 1642 (asymmetrical $\mathrm{COO}^{-}$stretching), 1258 (glucan units), 1090-1051 (glycosidic bond) and $879 \mathrm{~cm}^{-1}$ (C-H ring vibration) $[14,15]$. Spectra of both CAV membranes (Fig. 1c-d) indicated that the characteristic bands of Cht and AV were proportional to the ratio between the components in the blends. However, the $\mathrm{NH}$ and $\mathrm{CO}$ absorption bands that occur in the range $1654-1670 \mathrm{~cm}^{-1}$ were covered by a single band at $1659 \mathrm{~cm}^{-1}$ in the CAV spectrum (Fig. 1c) and $1672 \mathrm{~cm}^{-1}$ in the CAV1 spectrum (Fig. 1d), which suggests that Cht and AV could present specific interactions. Different authors have shown that Cht interacts with selected negatively charged molecules such as proteins, anionic polysaccharides and nucleic acids $[16,17]$. As AV is composed of a complex mixture of polysaccharides and proteins, among other compounds [2], specific interactions such as, for example, hydrogen bonding can occur between Cht and AV, which could explain the observed bond displacement.

Boyan et al. [18] reported that the surface properties of biomaterials, namely the chemistry, topography and/or surface energy can influence cell adhesion and proliferation and consequently the performance (rejection or acceptance) of a potential device. Therefore, changes in the surface topography of the membranes at the nanometer level were evaluated by AFM. The surface roughness of the blended membranes at the nanoscale level was higher than that of Cht (Table 1). Similar results have been observed previously [19], suggesting that the presence of AV can promote a rearrangement of the macromolecules in the blended system, which is reflected in changes in surface roughness.

The measured contact angles and, the calculated surface energies of the studied membranes are summarized in Table 1 . The results indicated that CAV was slightly more hydrophilic than Cht, while CAV1 was more hydrophobic. As mentioned before, AV contains a number of polysaccharides, proteins and other compounds [2]. Mixing with Cht could promote structural rearrangement, which could expose hydrophobic or hydrophilic groups on the material surface that could help explain the obtained findings. From the surface energy calculated using the OWR K method [12] it can be seen that both CAV and CAV1 presented significantly higher superficial energy values $(\gamma)$ in comparison with Cht, suggesting that these membranes have reactive surfaces. Additionally, the polar component $\left(\gamma_{\mathrm{p}}\right)$ value can be used as an estimation of the concentration of polar groups on the polymer surface [20]. The alteration in $\gamma_{p}$ of both CAV and CAV1 indicated different densities of polar groups on the material surfaces, which can be used to tailor the wettability. 
Table 1

Summary of the physical properties of the developed membranes.

\begin{tabular}{|c|c|c|c|c|c|c|}
\hline Membrane & Thickness $(\mu \mathrm{m})$ & Roughness (nm) & $\theta_{\text {glycerol }}\left({ }^{\circ}\right)$ & $\gamma\left(\mathrm{mN} \mathrm{m}^{-1}\right)$ & $\gamma_{\mathrm{d}}\left(\mathrm{mN} \mathrm{m}^{-1}\right)$ & $\gamma_{\mathrm{p}}\left(\mathrm{mN} \mathrm{m}^{-1}\right)$ \\
\hline Cht & $178 \pm 4.5$ & $3.8 \pm 0.5$ & $88.4 \pm 0.9$ & $19.3 \pm 0.02$ & $13.3 \pm 0.02$ & $6.0 \pm 0.01$ \\
\hline CAV & $248.2 \pm 2.7$ & $5.4 \pm 1.0$ & $86.4 \pm 2.8$ & $24.8 \pm 0.01$ & $21.7 \pm 0.01$ & $3.1 \pm 0.01$ \\
\hline CAV1 & $180 \pm 2.5$ & $18.4 \pm 6.0$ & $93.9 \pm 2.9$ & $30.4 \pm 0.01$ & $30.0 \pm 0.02$ & $0.41 \pm 0.01$ \\
\hline
\end{tabular}

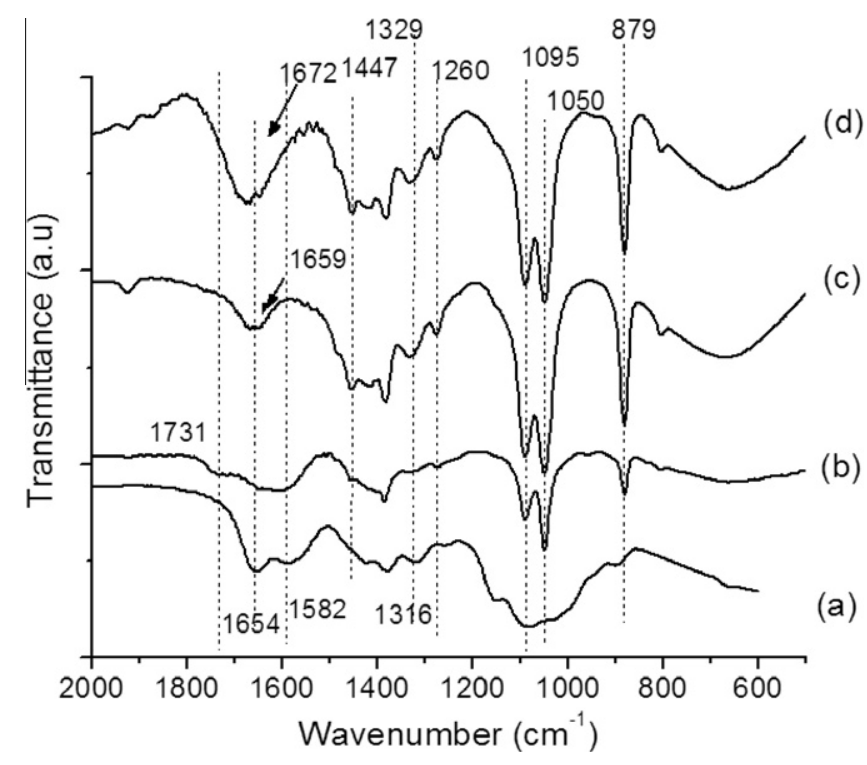

Fig. 1. FTIR spectra of the samples: (a) Cht; (b) AV; (c) CAV; (d) CAV1.

An ideal wound dressing material should show gradual degradation and reabsorption of the matrix by the host [4,21]. Enzymatic degradation of the developed membranes was investigated using lysozyme, an enzyme present in human serum [22] that could be responsible for enzymatic hydrolysis of Cht-based materials in vivo [23]. This enzyme is present in human serum at concentrations in the range $7-13 \mathrm{mg} \mathrm{l}^{-1}$. All membranes were incubated in PBS (control) and PBS containing lysozyme for up to 30 days. Fig. 2 displays the water uptake (Fig. 2a) and degradation profiles of the membranes (Fig. 2b) during the study period. Both CAV and CAV1 showed higher water uptake in comparison with the Cht membrane. This result is probably a consequence of the increase in hydrophilic groups in the blended system due to the addition of AV. Some studies have revealed that the water uptake behavior of Cht-based-systems depends on the blend composition. In fact, the AV gel is rich in hydroscopic polysaccharides such as acemannan [2], which, together with the hydrophilicity of Cht, results in greater swelling of the blended membranes in comparison with the Cht membrane. Furthermore, the high swelling ability of the membranes over a longer period not only provides a high moisture level at the wound-dressing interface but also allows absorption of any excess exudate. An analysis of the degradation profiles (Fig. 2b) indicated that Cht membranes show less weight loss compared with both CAV and CAV1 with time. Statistical analysis of the weight loss data showed significant differences $(p<0.05)$ on day 21 between the pairs Cht/CAV1 and CAV/CAV1. Differences were also found on day 28 for Cht relative to both CAV and CAV1. It has been reported that the degradation rate of Cht depends on the crystallinity, morphology and molecular weight, among other factors [24]. In fact, the degradation kinetics of Cht appear to be inversely related to the degree of deacetylation $[25,26]$. Thus, the high degree of deacetylation (76\%) of the Cht used in this work could lead to slower degradation. Moreover, both CAV and CAV1 showed highest weight loss (22\% and $25 \%$, respectively) after

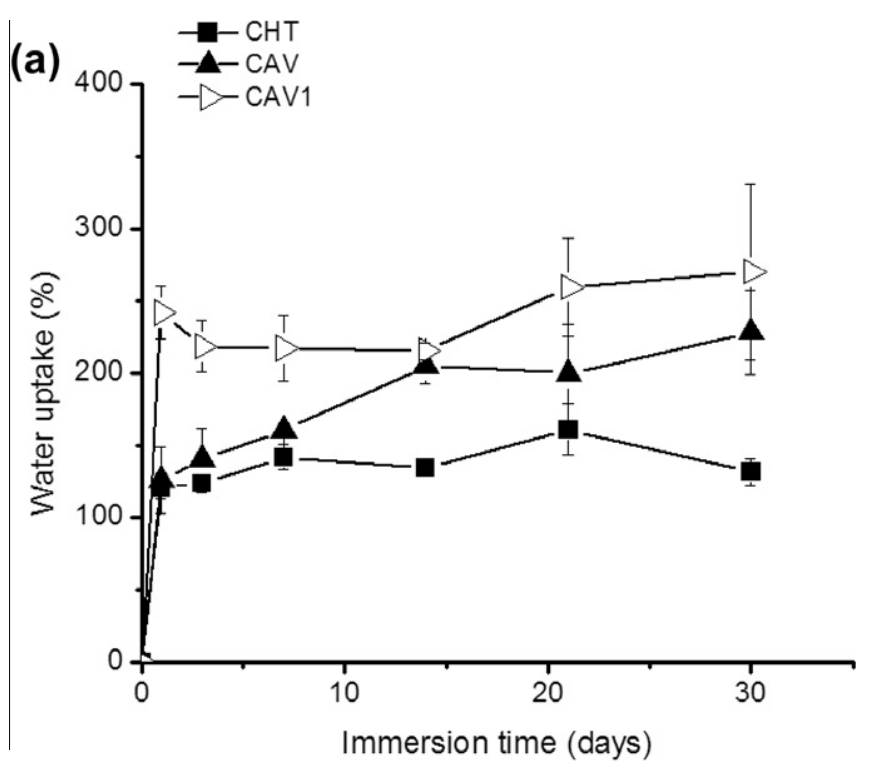

(b)

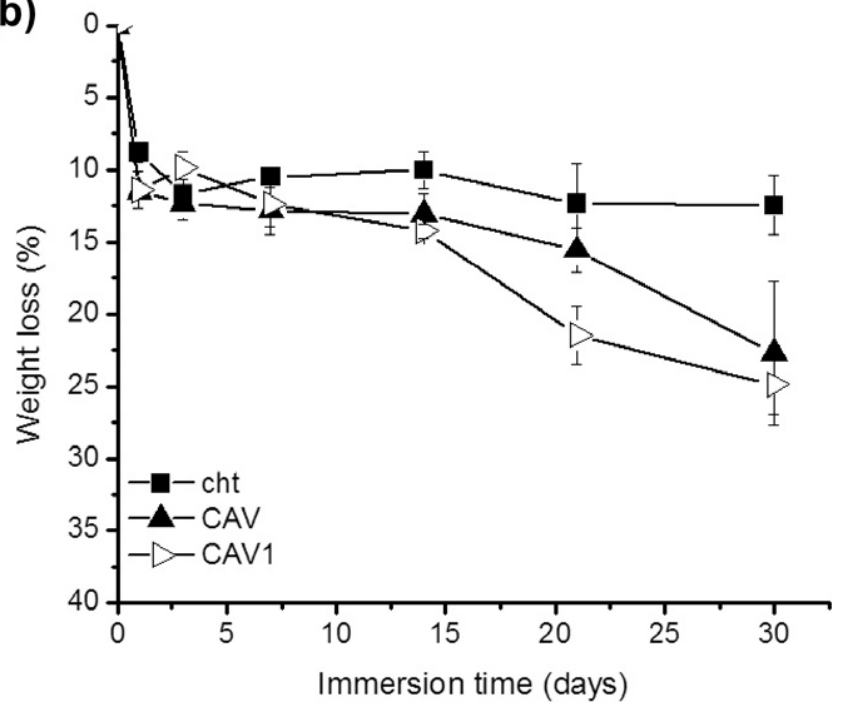

Fig. 2. (a) Water uptake and (b) weight loss of the Cht, CAV and CAV1 membranes as a function of immersion time in PBS containing $13.6 \mathrm{mg} \mathrm{l}^{-1}$ lysozyme at $37^{\circ} \mathrm{C}$. Data represent means \pm standard deviations ( $p<0.05$, two-way ANOVA).

longer incubation times (21 and 28 days). The high solubility of $\mathrm{AV}$ in aqueous media associated with different $\mathrm{Cht} / \mathrm{AV}$ ratios could be reasons for these findings.

Characterization of the mechanical properties of dressing materials is important since film dressings should be durable, stressresistant and flexible to facilitate routine handling [4]. The mechanical properties of the developed membranes were investigated by DMA. Fig. 3 presents the viscoelastic behavior of the membranes in terms of the storage (elastic) modulus $E^{\prime}$ and the loss factor $\tan \delta$. Mechanical analysis of the membrane made of AV gel alone was not conducted as the film was too fragile to handle. As shown in Fig. 3a, $E^{\prime}$ of all membranes tended to increase 

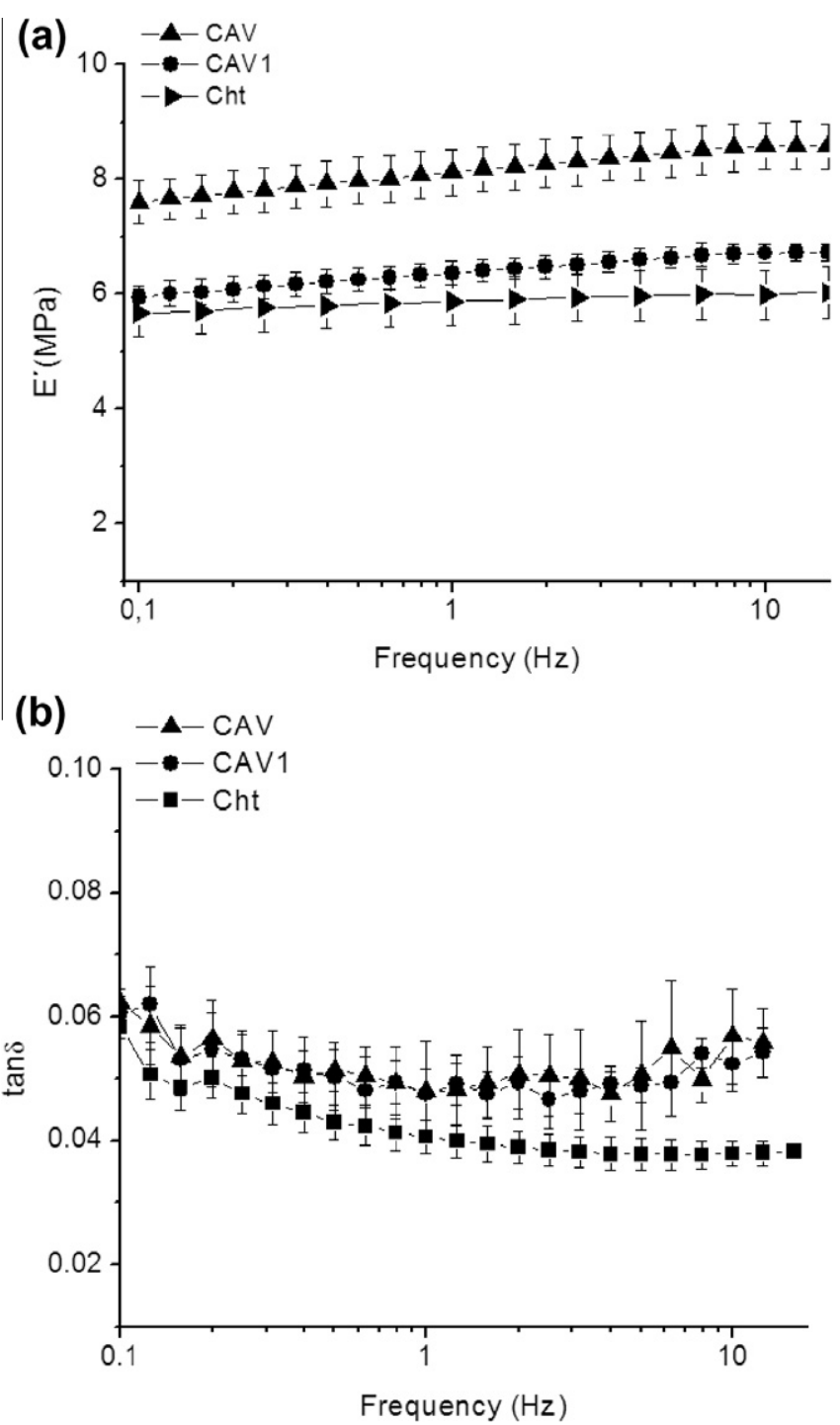

Fig. 3. Evaluation of the viscoelastic properties of all the developed membranes by DMA. Frequency scans were performed in the range $0.1-10 \mathrm{~Hz}$ under wet conditions at $37^{\circ} \mathrm{C}$. (a) $E^{\prime}$ of Cht, CAV and CAV1 membranes; (b) tan $\delta$ of Cht, CAV and CAV1 membranes.

with increasing frequency. The results reveal that both CAV and CAV1 were stiffer than Cht alone membranes, exhibiting the highest $E^{\prime}$ values. Statistical differences $(p<0.05)$ were observed for CAV in relation to CAV1 and Cht. A comparison between CAV and CAV1 indicated that the CAV1 membrane (cht/AV ratio $1: 1$ ) has the lowest $E^{\prime}$ value, which could be related to the greater amount of $\mathrm{AV}$ involved in the preparation of this membrane. Fig. 3b presents the variation in $\tan \delta$ with frequency. The loss factor measures the damping properties of the samples and provides an indication of its viscoelastic characteristics [27]. Such behavior indicates that the molecules in the membranes present long relaxation times, which allow recovery of such materials. Human skin tissue is a complex viscoelastic composite with a rigidly elastic upper epidermal layer and an underlying viscoelastic dermal layer [28,29]. Thus the mechanical responses of both CAV and CAV1 associated with their viscoelastic nature could be suitable for skin healing applications.

Wounds are frequently contaminated with a variety of bacteria, so the potential for infection is always present. This has encouraged the development of improved wound dressings that show an antimicrobial effect through the incorporation or not of antimicrobial agents. Evaluation of the antimicrobial activity of the developed membranes against $S$. aureus, a Gram-negative wound pathogen, was carried out using two methods: the bacterial cell suspension and agar diffusion methods. Staphylococcus aureus was chosen for this study due to its frequent presence in skin wounds [30]. The findings from the bacterial cell suspension method (Fig. 4) indicate that the antibacterial activities of CAV and CAV1 are better than that of Cht membranes, suggesting that the addition of AV to Cht enhanced the antimicrobial potential of the resulting membranes. However, statistical differences $(p<0.05)$ were not found between the CAV and CAV1 membranes.

Furthermore, the membranes exhibited various sizes of inhibitory halo in vitro, as verified by the agar diffusion method. CAV1 (inhibition zone diameter $4.9 \mathrm{~cm}$ ) had the highest antibacterial potential compared with the other formulations (Cht $0 \mathrm{~cm}$, CAV $4.7 \mathrm{~cm}$ ) (see Fig. 5). Although CAV and CAV1 showed similar inhibition zone diameters, it can be seen in Fig. 5 that CAV1 presented a much better defined and clearer halo. This demonstrates the greater effectiveness of CAV1 as a bactericide. The higher antibacterial potential displayed by the CAV1 membranes could be a result of the higher greater content of $\mathrm{AV}$ in the membrane, which consequently increases its inhibitory potency. Additionally, no significant antimicrobial activity was found for Cht membranes. The mechanism of antimicrobial activity of Cht has not yet been fully elucidated, but the most feasible hypothesis is a change in cell permeability due to interactions between the net positive charge of Cht and the negatively charged bacterial cell walls, resulting in cell wall breakage and cell death $[31,32]$. According to the literature, the antimicrobial activity of Cht depends on its molecular weight, degree of deacetylation, chitosan derivatization, $\mathrm{pH}$ of the solution and the target microorganism [32,33]. Zheng et al. [33] found that antibacterial activity increased with increasing molecular weight of Cht (305 kDA). Thus it is possible that the characteristics of the Cht used in this work (degree of deacetylation $76.6 \%$, molecular weight $115 \mathrm{kDA}$ ) could have influenced the results obtained. In turn, AV gel has been shown to be an effective antimicrobial agent against Gram-positive and Gram-negative bacteria, including $S$. aureus, Escherichia coli and Klebsiella pneumonia [34,35]. Also, topical application of AV has been shown to be effective in the treatment of various skin problems such as, for example, burns and eczema [36]. The mechanism of action of AV is still not fully understood, but some studies [34] have suggested that certain compounds such as acemannan, anthroquinones and salicylic acid, present in $\mathrm{AV}$, may be responsible for its antimicrobial activity. Further in vivo assays will be necessary to gain a better understanding of the antimicrobial efficacies of these membranes.

The wound healing process is complex and involves the interaction of many different types of cells and matrix components to

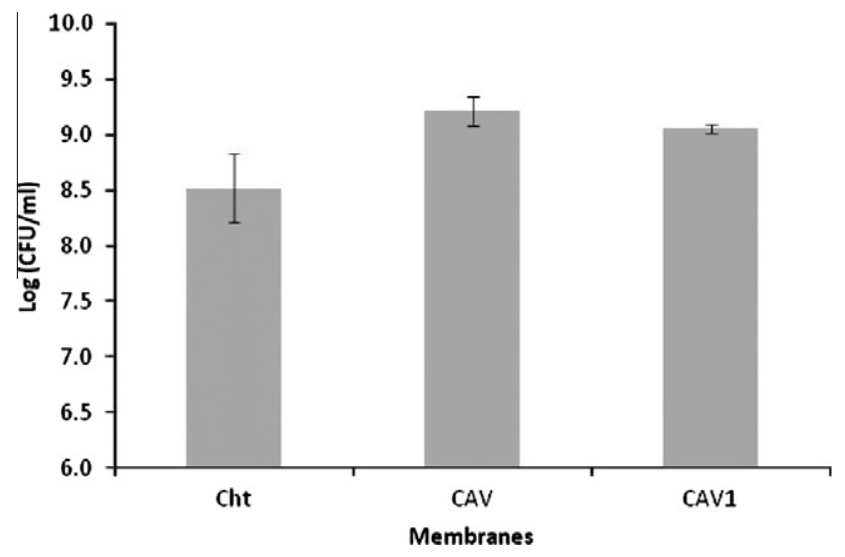

Fig. 4. Cell viability tests obtained after bacterial cell suspension assay (24 h). 


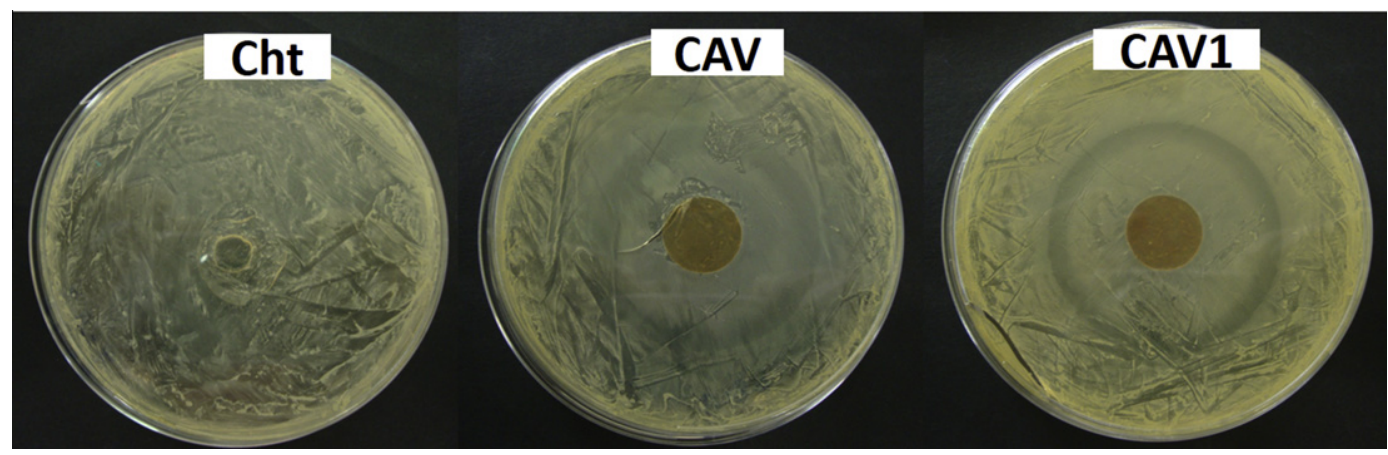

Fig. 5. Photographic image of the developed membranes (Cht, CAV and CAV1) on culture plates inoculated with S. aureus after 72 h.

establish a provisional and eventually a complete regenerated tissue [37]. Thus hDFs were used in vitro to assess the cell response to the developed membranes. The alamar blue results (Fig. 6) reveal that the hDFs were less metabolically active when cultured on Cht. Interestingly, significantly higher cell metabolic activity $(p<0.05)$ was found for CAV compared with the other membranes on days 7 and 15 . The DNA results (Fig. 7) showed a significantly higher number of cells $(p<0.05)$ attached to CAV membranes on days 7 and 15 compared with CAV1 and Cht, indicating that hDFs were unable to proliferate on these membranes. These findings are in agreement with cell metabolic activity results (Fig. 6).

Furthermore, the calcein-AM results (Fig. 8) are in agreement with the findings obtained from the alamar blue assay and DNA quantification, suggesting that they are viable independent of the cell number present on the membrane surface. On the Cht membrane (Fig. 8a) hDFs exhibited a round morphology with cell agglomeration throughout the study period. Cells seeded on the CAV membrane showed better spreading and a higher number of cells attached to the surface. From days 1 to 7 the cells were uniformly distributed on the surface of the CAV membrane, exhibiting a spindle-like shape typical of fibroblasts, suggesting good adherence to this surface. Moreover, on day 7 hDFs were well spread on and were able to adhere to both sides of the CAV membrane surface. Despite the good cell adhesion and proliferation observed

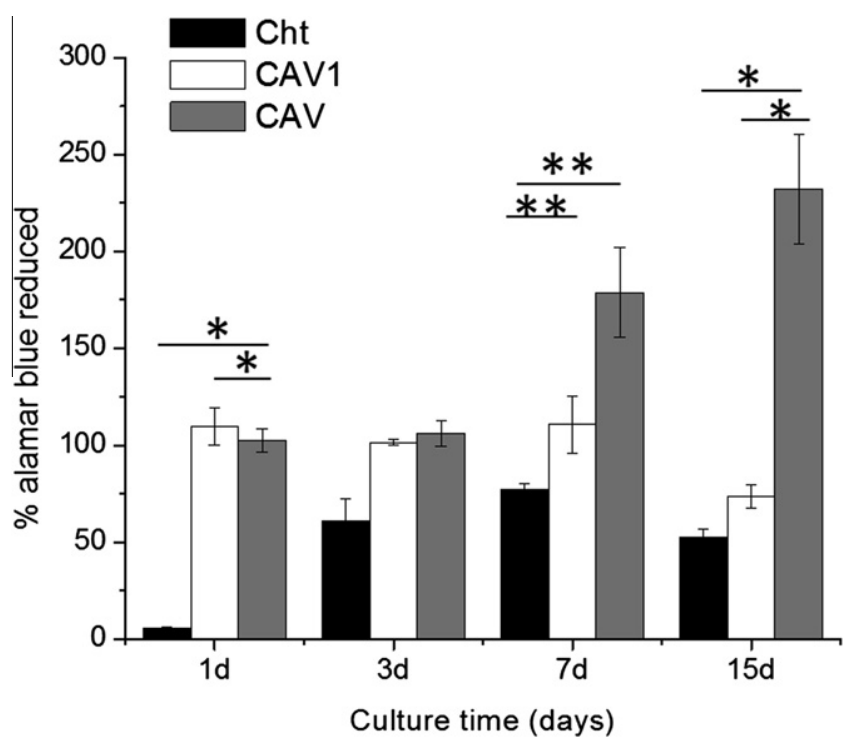

Fig. 6. Alamar blue results for hDFb cells cultured on the developed membranes as a function of time. The values were normalized to results obtained on TCPS, which was used as a positive control. Data are presented as means \pm standard deviations $(p<0.05$, two-way ANOVA).

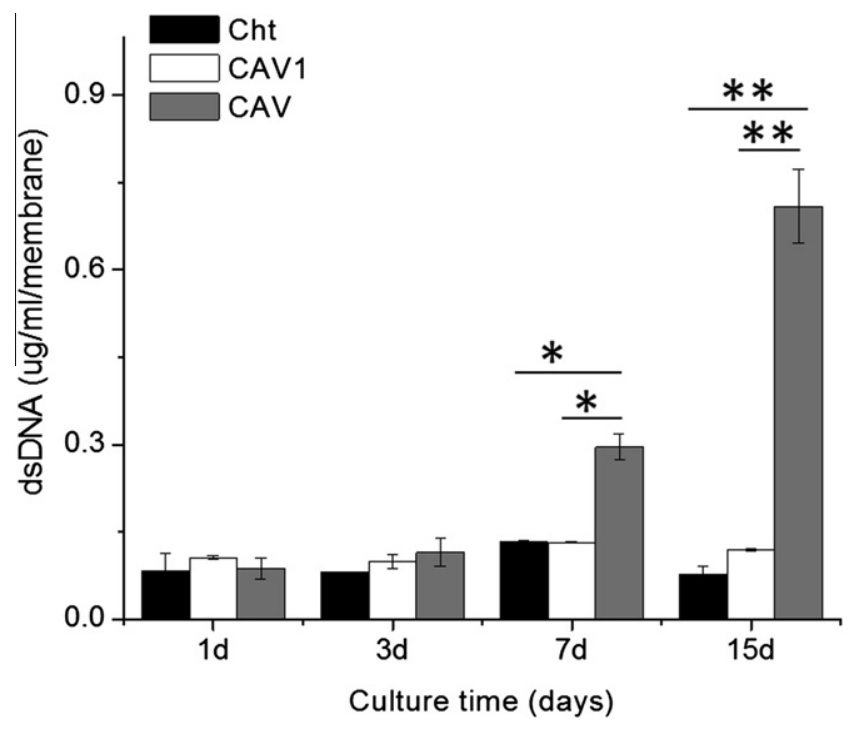

Fig. 7. dsDNA content of hDFb cells adherent on the developed membranes as a function of culture time. Data are presented as means \pm standard deviations $(p<0.05$, two-way ANOVA).

on the CAV membrane, the higher AV content of CAV1 did not result in the expected increase in cell spreading and proliferation.

According to the literature [38] unmodified Cht membranes are unable to promote fibroblast cell attachment and proliferation, perhaps as a result of the monopolar basic nature of Cht, which does not interact well with the bipolar bovine serum extracellular matrix proteins present in the culture medium. The findings obtained in this work indicate that the surfaces of the blended membranes varied not only in roughness but also in AV and Cht functional groups and surface energy. Generally, the surface energy and wettability of biomaterials significantly affect biological processes at the subcellular (protein adsorption) and cellular (cell attachment, spreading, proliferation, etc.) levels [39]. In Cht membranes, for instance, surface modification by blood plasma has demonstrated a significant improvement in fibroblast adhesion and proliferation as a result of changes in both surface roughness and energy [11]. In turn, the biological activity of Cht/AV-based membranes can also be influenced by physical features such as the surface energy, topography and stiffness, which directly influence protein adsorption and, subsequently, the cell response. Chitra et al. [40] reported that an AV gel can accelerate wound healing in diabetic rats due to its ability to stimulate fibroblasts and enhance the processes of wound healing, such as collagen synthesis and maturation and wound contraction. The noted differences in cell response on CAV became more evident with increasing culture 

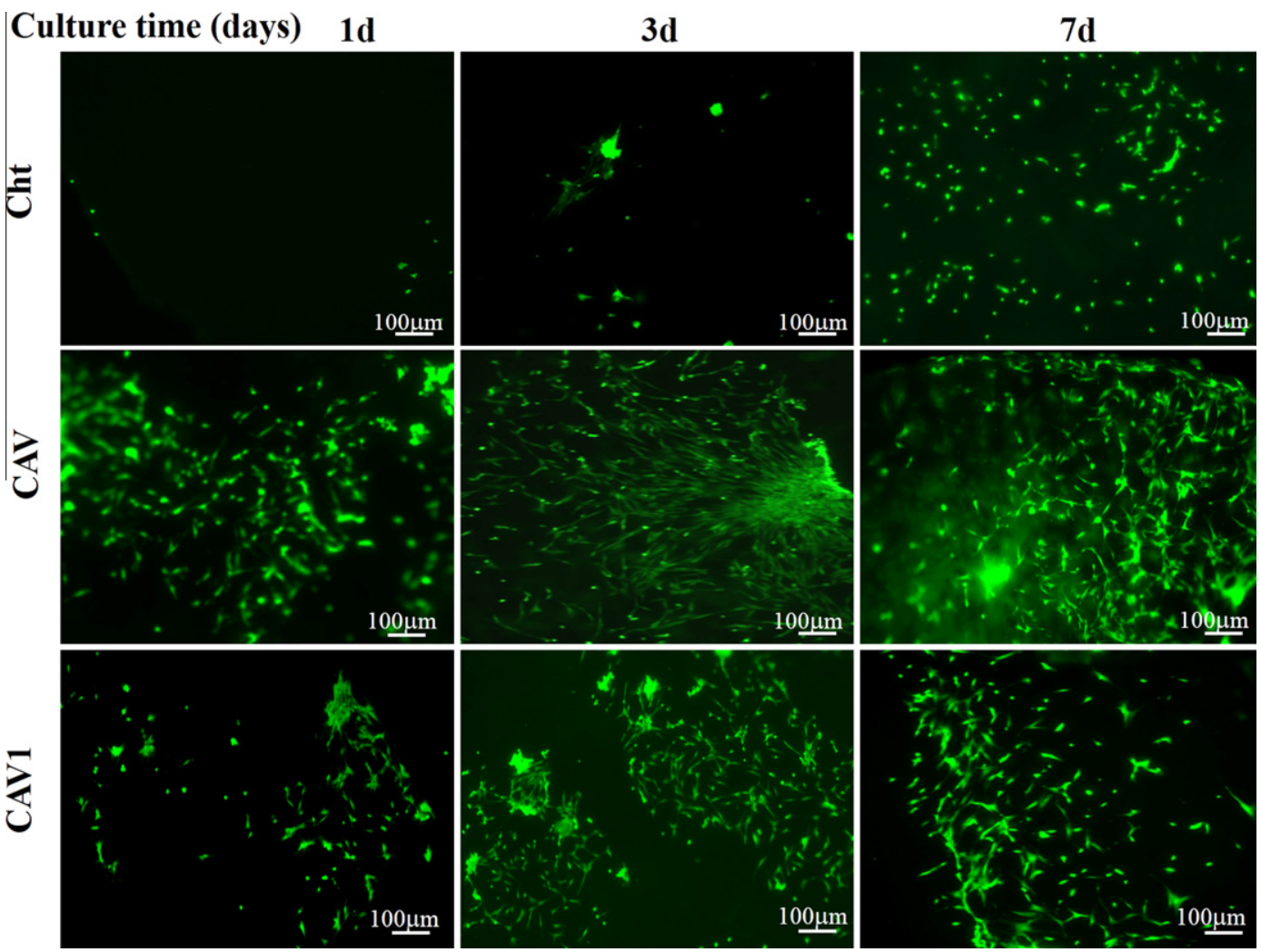

Fig. 8. Calcein-AM staining of hDFb cells cultured for 1,3 and 7 days on the membranes (Cht, CAV and CAV1).

time, suggesting that the incorporation of AV has a positive effect on the long-term material response. Depending on the type of wound, both membranes (CAV and CAV1) could be useful as wound dressing materials. CAV, for example, shows good cell adhesion and proliferation, and could be used for long-term wound healing, during which the membranes will be resorbed by the body during the healing process. On the other hand, the CAV1 membrane could be used for short-term or acute wounds (1-4 days), similarly to traditional wound dressings. Furthermore, the risk of further damage during membrane removal is low, since cells did not adhere well to this surface.

\section{Conclusions}

This work has demonstrated the potential of native AV gel incorporated in Cht to create blended membranes. In the developed Cht/AV-based membranes the incorporation of even a small amount of AL gel into Cht provided blended membranes with adequate roughness, degradation rate, wettability and mechanical properties. Moreover, the in vitro biological performance revealed that Cht/AV-based membranes offer a good environment for hDF attachment, spreading, proliferation and viability. Overall, the effect of Cht/AV-based membranes on bacterial growth and the relatively good cellular response, together with suitable mechanical and physical properties, suggest that these blended membranes may be useful as wound dressings. Further studies should be pursued to elucidate the mechanism of action in vivo of these blended membranes.

\section{Acknowledgements}

The authors acknowledge financial support from the Portuguese Foundation for Science and Technology (grants SFRH/BPD/45307/ 2008 and SFRH/BD/64601/2009), the "Fundo Social Europeu", and the "Programa Diferencial de Potencial Humano". This work was partially supported by the FEDER through POCTEP 0330_IBEROMARE_1_P.

\section{Appendix A. Figures with essential color discrimination}

Certain figures in this article, particularly Figs. 5 and 8, are difficult to interpret in black and white. The full color images can be found in the on-line version, at http://dx.doi.org/10.1016/j. actbio.2013.02.027.

\section{References}

[1] Wink M. Medicinal plants: a source of anti-parasitic secondary metabolites. Molecules 2012;17:12771-91.

[2] Hamman JH. Composition and applications of Aloe vera leaf gel. Molecules 2008;13:1599-616.

[3] Eshun K, He Q. Aloe vera: a valuable ingredient for the food, pharmaceutical and cosmetic industries - a review. Crit Rev Food Sci 2004;44:91-6.

[4] Boateng JS, Matthews KH, Stevens HNE, Eccleston GM. Wound healing dressings and drug delivery systems: a review. J Pharm Sci 2008;97:2892-923.

[5] Vazquez B, Avila G, Segura D, Escalante B. Antiinflammatory activity of extracts from Aloe vera gel. J Ethnopharmacol 1996;55:69-75

[6] Zhang L, Tizard I. Activation of mouse macrophage cell line by acemannan; the major carbohydrate fraction of aloe vera. Immunopharmacology 1996;35:119-28.

[7] Rinaudo M. Chitin and chitosan: properties and applications. Prog Polym Sci 2006;31:603-32.

[8] Silva SS, Mano JF, Reis RL. Potential applications of natural origin polymerbased systems in soft tissue regeneration. Crit Rev Biotechnol 2010;30:200-21.

[9] Silva SS, Mano JF, Reis RL. Soft constructs for skin tissue engineering. In: Mano JF, editor. Biomimetic approaches for biomaterials developments. Weinheim, Germany: Wiley-VCH; 2012. p. 537-57.

[10] Signini R, Filho S. Characteristics and properties of purified chitosan in the neutral, acetate and hydrochloride forms. Polímeros Ciência e Technologia 2001;11:58-64.

[11] Silva SS, Luna SM, Gomes ME, Benesch J, Paskuleva I, Mano JF, et al. Plasma surface modification of chitosan membranes: characterization and preliminary cell response studies. Macromol Biosci 2007;8:568-76.

[12] Owens DK, Wendt RC. Estimation of the surface free energy of polymers. J Appl Polym Sci 1969;13:1741-7. 
[13] Brugnerotto J, Lizardi J, Goycoolea FM, Argüelles-Monal W, Desbrières J, Rinaudo M. An infrared investigation in relation with chitin and chitosan characterization. Polymer 2001;42:3569-80.

[14] Inpanya P, Faikrua A, Ounaroon A, Sittichokechaiwut A, Viyoch J. Effects of the blended fibroin/aloe gel film on wound healing in streptozotocin-induced diabetic rats. Biomed Mater 2012;7. doi: http://dx.doi.org/10.1088/1748$6041 / 1087 / 1083 / 035008$.

[15] Chang XL, Chen BY, Feng YM. Water-soluble polysaccharides isolated from skin juice, gel juice and flower of Aloe vera Miller. J Taiwan Inst Chem E 2011;42:197-203.

[16] Silva SS, Goodfellow BJ, Benesch J, Rocha J, Mano JF, Reis RL. Morphology and miscibility of chitosan/soy protein blended membranes. Carbohydr Polym 2007;70:25-31.

[17] Wang LH, Khor E, Wee A, Lim LY. Chitosan-alginate PEC membrane as a wound dressing: assessment of incisional wound healing. J Biomed Mater Res 2002;63:610-8.

[18] Boyan BD, Hummert TW, Dean DD, Schwartz Z. Role of material surfaces in regulating bone and cartilage cell response. Biomaterials 1996;17:137-46

[19] Silva SS, Caridade SG, Mano JF, Reis RL. Effect of crosslinking in chitosan/aloe vera-based membranes for biomedical applications. Carbohyd Polym 2013, Submitted for publication.

[20] Lopez-Perez PM, Marques AP, Silva RMP, Pashkuleva I, Reis RL. Effect of chitosan membrane surface modification via plasma induced polymerization on the adhesion of osteoblast-like cells. J Mater Chem 2007;17:4064-71.

[21] Petrulyte S. Advanced textile materials and biopolymers in wound management. Dan Med Bull 2008;55:72-7.

[22] Henry JB. Clinical diagnosis and management by laboratory methods. In: Henry JB, editor. Clinical diagnosis and management by laboratory methods. Philadelphia, PA: WB Saunders; 1991. p. 1371.

[23] Ren D, Yi H, Wang W, Ma X. The enzymatic degradation and swelling properties of chitosan matrices with different degrees of $\mathrm{N}$-acetylation. Carbohydr Res 2005;340:2403-10.

[24] Lee D, Lim H, Chong H, Shim W. Advances in chitosan material and its hybrid derivatives: a review. Open Biomater J 2009;1:10-20.

[25] Moghaddasi M, Verma S. Aloe vera their chemicals composition and applications: a review. Int J Biol Med Res 2011;2:466-71.

[26] Martins A, Pereira R, Leonor I, Azevedo H, Reis RL. Chitosan scaffolds incorporating lysozyme into CaP coatings produced by biomimetic route: a novel concept for tissue engineering combining a self-regulated degradation system with in situ pore formation. Acta Biomater 2009;5:3328-36.

[27] Mano JF. Viscoelastic properties of chitosan with different hydration degrees as studied by dynamic mechanical analysis. Macromol Biosci 2008;8:67-76.

[28] Holt B, Tripathi A, Morgan J. Viscoelastic response of human skin to low magnitude physiologically relevant shear. J Biomech 2008;41:2689-95.

[29] Silver F, Freeman J, Devore D. Viscoelastic properties of human skin and processed dermis. Skin Res Technol 2001;7:18-23.

[30] Bowler P, Duerden B, Armstron D. Wound microbiology and associated approaches to wound management. Clin Microbiol Rev 2001;14:244-69.

[31] Devlieghere F, Vermeulen A, Debevere J. Chitosan: antimicrobial activity, interactions with food components and applicability as a coating on fruit and vegetables. Food Microbiol 2004;21:703-14.

[32] Rabea EI, Badawy MET, Stevens CV, Smagghe G, Steurbaut W. Chitosan as antimicrobial agent: applications and mode of action. Biomacromolecules 2003:4:1457-65.

[33] Zheng L-Y, Zhu J-F. Study on antimicrobial activity of chitosan with different molecular weights. Carbohydr Polym 2003;54:527-30.

[34] Pandey R, Mishra A. Antibacterial activities of crude extract of aloe barbadensis to clinically isolated bacterial pathogens. Appl Biochem Biotechnol 2010;160:1356-61.

[35] Ndhlala AR, Amoo SO, Stafford GI, Finnie JF, Van Staden J. Antimicrobial, antiinflammatory and mutagenic investigation of the South African tree aloe (Aloe barberae). J Ethnopharmacol 2009;124:404-8.

[36] Arunkumar S, Muthuselvan M. Analysis of phytochemical constituents and antimicrobial activities of Aloe vera L. against clinical pathogens. World J Agric Sci 2009;5:572-6.

[37] Velnar T, Bailey T, Smrkoli V. The wound healing process: an overview of the cellular and molecular mechanisms. J Int Med Res 2009;37:1528-42.

[38] Zhu X, Chian KS, Chan-Park MBE, Lee ST. Effect of argon-plasma treatment on proliferation of human-skin-derived fibroblast on chitosan membrane in vitro. J Biomed Mater Res A 2005;73A:264-74.

[39] Kim MS, Khang G, Lee HB. Gradient polymer surfaces for biomedical applications. Prog Polym Sci 2008;33:138-64.

[40] Chithra P, Sajithlal GB, Chandrakasan G. Influence of aloe vera on the healing of dermal wounds in diabetic rats. J Ethnopharmacol 1998;59:195-201. 